\title{
All-Russian contest: "I am a Professional" in photonics: the first light
}

\section{Anna Voznesenskaya, Galina Romanova}

Anna Voznesenskaya, Galina E. Romanova, "All-Russian contest: "I am a Professional" in photonics: the first light," Proc. SPIE 10741, Optics Education and Outreach V, 107410R (14 September 2018); doi: 10.1117/12.2321278

Event: SPIE Optical Engineering + Applications, 2018, San Diego, California, United States 


\title{
All-Russian Contest "I am a Professional" in Photonics: the first light
}

\author{
Anna Voznesenskaya, Galina E. Romanova* \\ ITMO University, 49 Kronverksky pr., St. Petersburg, Russia, 197101
}

\begin{abstract}
The contest "I am a professional" is an all-Russian contest that includes many competitions in various fields: from the humanitarian sciences to the technical fields (sociology, economics, psychology, IT, physics, etc.). Several fields already tried this format, but for the photonics it was the first trial.

The goal of such contest concludes in the massive involvement of undergraduate and graduate students into solution of tasks from various areas of modern photonics - from material science till light design and AR/VR systems.

Despite main part of the contest is provided by the ITMO University and its regional partners, a set of leading industry companies supported the contest. Their motivation is in direct communication with talented students - future professionals.

This challenging project poses many tasks and makes the organization committee and the team who prepares the event to solve many tasks: organize network collaboration between many universities and industry companies to prepare the content for the event, notify the potential participants, motivate them (both sides), hold the contest in the same time with many participants over the big country and check the tasks in various fields by the experts.
\end{abstract}

We present our experience in organization of such an event and discuss some features, results and perspectives.

Keywords: contest in Photonics, education in optics, engineering education, problem-based learning

\section{INTRODUCTION}

Contests on various subject areas for students and schoolchildren are a common practice. Mathematics, robotics, programming, language are especially popular. Thus, competitions of different types in many subject areas are held regularly and for a long time, but are usually limited to the region where it is held. The goal of all competitions is to test the level of knowledge on a discipline, select the most talented students and give them more opportunities for selfrealization. The second goal is to identify problem areas and regions, as well as gaps in knowledge.

The idea of the All-Russian Contest "I am a Professional" is to conduct a total examination of the educational results of modern students at the state level, and to do this in many areas simultaneously. The strategic goal of the project is to reduce the gap between the content of university programs and the requirements of employers. Therefore, one of the key features of the Contest is the practice-oriented cases, with relevant contents. In their development, experts from leading industrial companies were planned to be involved. The quality of participation in the national students' Contests is an important indicator of the activity of universities and regions of Russia, as well as an indicator of the openness of higher education to cooperation with the real sector of the economy and industry. ITMO University oversaw three major directions of this all-Russian Contest: "Photonics", "Computer Science", and "Cybersecurity"1.

Despite the great experience of holding contests and competitions of this type at different levels ${ }^{2-5}$, organizers had to solve many tasks during the preparing and conducting. Such problems are organizational and technical problems (that are notification of the participants, organization of tours, organization of checking, persons to be a in the Jury and the methodological commission, appeals, etc.) and problems of contents - selection of tasks, their grading, balance on complexity and subject arear, etc. Given the two levels of education adopted in almost all universities of the country, it is necessary to consider separately the level of undergraduates and graduates.

In this work we will talk about some of the challenges and our experience of overcoming them.

*romanova_g_e@ mail.ru; phone +7 812 595-41-65; www.ifmo.ru, aco.ifmo.ru

Optics Education and Outreach V, edited by G. Groot Gregory, Proc. of SPIE Vol. 10741, 107410R

(C) 2018 SPIE · CCC code: 0277-786X/18/\$18 - doi: 10.1117/12.2321278 


\section{THE FIRST ROUND}

The title Photonics is often understood as the science of the interaction of light with matter. In our case the contest "I am a Professional", Photonics track is in fact a unification of all areas of optics - geometric and applied optics, laser technologies, optoelectronics, new materials and photonics devices, nanotechnologies, part of ophthalmology, physical and theoretical optics, light design, optical design, etc .

Organizational structure of the Contest was solved as follows: the organizing committee interacts with the central office which is in charges for all the contest branches and receives instructions on the procedure for holding, communicates with the organization of PR services, etc.

As well as for many similar contests, the competition "I am a Profi" was held in two rounds, and the first stage is preliminary - it is a qualification round. Since participants from all over Russia were expected to attend (more than 1,000 people), it was clearly decided to organize the qualifying stage in the form of a test: this form allows to unify the check and create equal chances for all participants, and in addition to process the results of a large number of participants and select participants in the second stage.

Of cause, if the form of the contest is test, the importance of the choosing and balancing the tasks increases a lot. So, it is a great role of the methodical commission who selects and composes tasks, determines the number and form of tasks, determines the complexity of tasks. The Jury monitors the correctness of the automatic check of tasks, checks the work manually if necessary, solves the disputed points in the part of the results of the contest.

In addition, it was decided to do a test on the Yandex-Contest platform ${ }^{6}$, with automated verification of the answers: this is a well-known search system, and also a mail-service and cloud storage, etc.

The test form of the competition has both advantages and disadvantages: first and foremost, the automation of verification allows you to get results quickly and rank participants practically immediately. Among the disadvantages we would like to highlight the fact that the main work falls on the methodological commission, technical experts and the organizing committee.

The Methodical Commission together with the Jury decided to prepare 30 tasks for the each variant (one participant) in the qualifying test, the duration time 1 hour. About 50\% of the tasks concerned general physical optics, about $15 \%-$ laser technologies, about $15 \%$ - applied optics, $10 \%$ - photonics materials, $5 \%$ - general erudition in the field of optics, $5 \%$ - the latest photonics devices. To familiarize the participants with the technical issues and the content of the competition, a demo test was prepared.

The first round test could be taken from any place: from your home computer, Internet cafes, etc., so there was no control over the individuality, the use of any materials or other tips. The organizers were aware of this: with the number of tasks 30 and the time of completion of 1 hour, the participants, if they did not know the material and had no idea of how to solve the task, could not score enough points to pass the qualifying round. The tasks were not quite standard and required an understanding of the subject area.

As practice has shown, the number of tasks 30 fits the situation and allows ranking the participants rather accurately. The figure 1 shows the distribution of the results of the participants of the first round for graduates and undergraduates. It should be noted that the maximum grade was 100 .

Another one point that worth to highlight: taking into account the number of participants and the time difference through the country, as well as the time period (from December, 1 to December, 10), several equivalent tasks were needed to exclude the possibility of copying the solutions, joint decision and other cheating: the options for tasks variants were presented to participants randomly, so that even if two participants pass the test together and solve it together on neighboring computers, then different tasks can be shown on the same position or in other words, on the same position (for example, task number 5) where will be different tasks on different topics. If student tries to take the solution from the other, they spend extra time searching for relevant task, and thus loses time and chances to score more points for the test.

Types of tasks that were offered to participants:

1) A test where a participant should choose an answer (the word, the term, the definition, the number, etc.) of the proposed options. In some tasks there was one correct answer, in the others - several. In the last case if only one correct 
answer was selected, only a part of the scores was counted, if at least one wrong one is selected the task will bring zero points.

2) The task there the participant should to enter a number, the possible error of the answer was taken into account. So, the answer with some reasonable accuracy could be accepted.

3) The most rare type of the task was to enter the word. Here also possible grammatical errors and spelling differences were taken into account

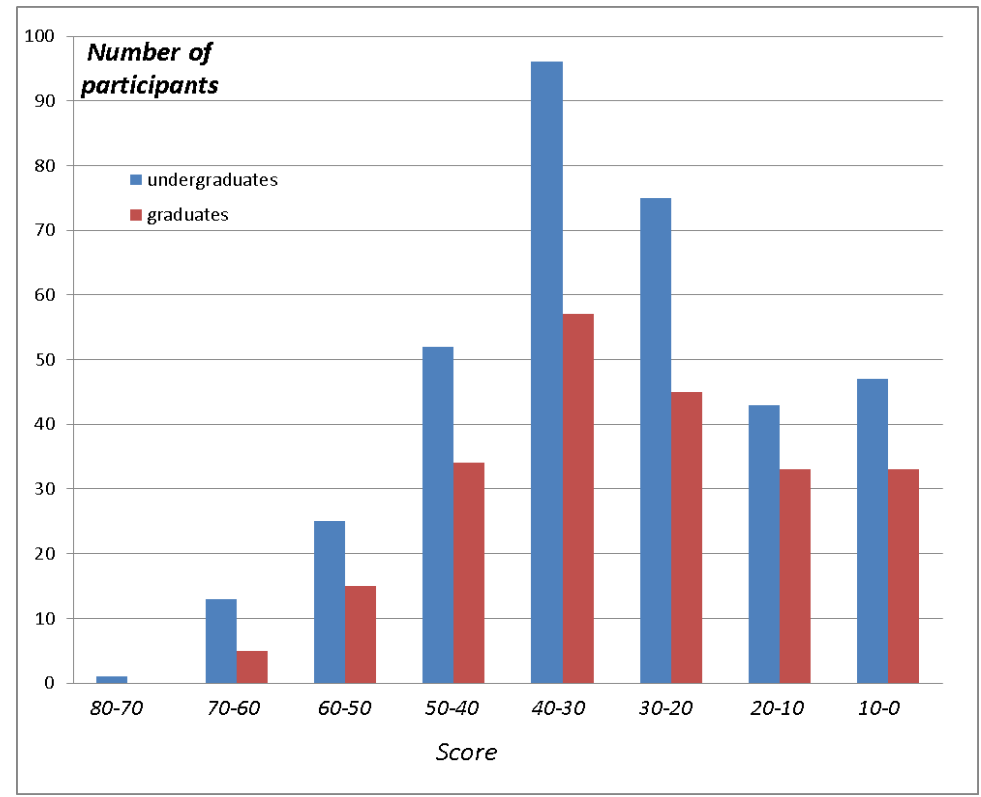

Figure 1. The score distribution of the participants of the first round

Of course, the contest usually should contain tasks of high complexity, but it is well known that it is necessary to include rather simple problems: the second goal of any contest is teaching and motivating. So, the tasks should be interesting enough and possibly non-standard in formulations and simple tasks that are supposed to solve everything allow participants to finish with a non-zero result and motivate them to continue the education.

As can be seen from the plots on the figure 1, the difference between the participants is quite large, that indicates a good balance of tasks by number and weight. It also can be seen, that both undergraduates and graduates has shown some average minimum result (up to approximately 30 - 35 points), and there are a few participants with high score.

For the second round participants who scored more than 40 points (for graduates) and more than 38 points for undergraduates were selected. It is important to note that the limiting score was not defined before, so we allow passing to the second round about $30 \%$ of the participants, and it is usually a normal ratio.

\section{THE SECOND ROUND}

The second round of the Contest is more important, because the winners are awarded based on the results of this round. The tasks of the final round were formed jointly with employers in the form of practical cases. The prizes and other preferences will be discussed later in the following parts of the paper.

For the second round, one day was chosen for all the tracks (in different areas): this primarily allows the organizers to prepare only one variant - the only one tasks combination. The second round is conducted only for internally: it is very important to monitor the individuality of the problems solution and no prompts, for extramural round we cannot implement this monitoring and control.

Since it was quite difficult to gather participants from all over Russia in one location at the same time at one time, this event was held in 5 locations (St. Petersburg, Moscow, Novosibirsk, Tomsk, and Orel). Partners and co-organizers of the ITMO University who provide facilities to organize the second tour were Siberian State University of Geosystems and 
Technologies ${ }^{7}$, National Research Nuclear University MEPhI (Moscow Engineering Physics Institute) ${ }^{8}$, Tomsk State University ${ }^{9}$, Orel State University ${ }^{10}$.

On the second round, it was officially allowed to use reference materials: in our experience, for many contests it is quite possible to allow the use reference literature (electronic or paper books brought with you or issued by the organizers). The important detail for the our case that one could use sheets with the formulas written out, but reference literature was not allowed to be used: first of all, with the number of participants in the second round, it is almost impossible to provide all the same sets of books and other materials in five cities. That is why the responsibility for the preparation and availability of such materials essentially shifted to the participants themselves. This is also some indicator and element of motivation: to preview possible subjects in advance including having got acquainted with them during the first, qualifying round, have about a month to prepare for the second round, during this time you can just look through the textbooks and decide what formulas you need to have with you.

The intramural contests can be organized in different ways. The most common option is a set of tasks or one large creative task, which is then evaluated by the Jury team. However, as in many cases, technical details determine the content: with a large number of participants, it is natural to either organize aa large Jury and check collegially the participants' solutions or try to make the checking process automatic. We choose the second path and decided to prepare a test. Thus, the focus of the work shifted from the checking the solutions by Jury to the composing the number of tasks and their balancing.

The difference from the first round was more complex tasks, more specific professional life assignments and less for general physical optics. The platform for the implementing is the center for distant education (CDE), ITMO University ${ }^{11}$. The platform is flexible enough and allows a variety of testing options. In this case, 40 free-access tasks were offered. That is, the test consisted of 40 tasks, which could be viewed in random order, see areas, complexity (number of points) and select which tasks that are more in-line with the participant's specialization. The photos from the second round are shown on the figure 2 .
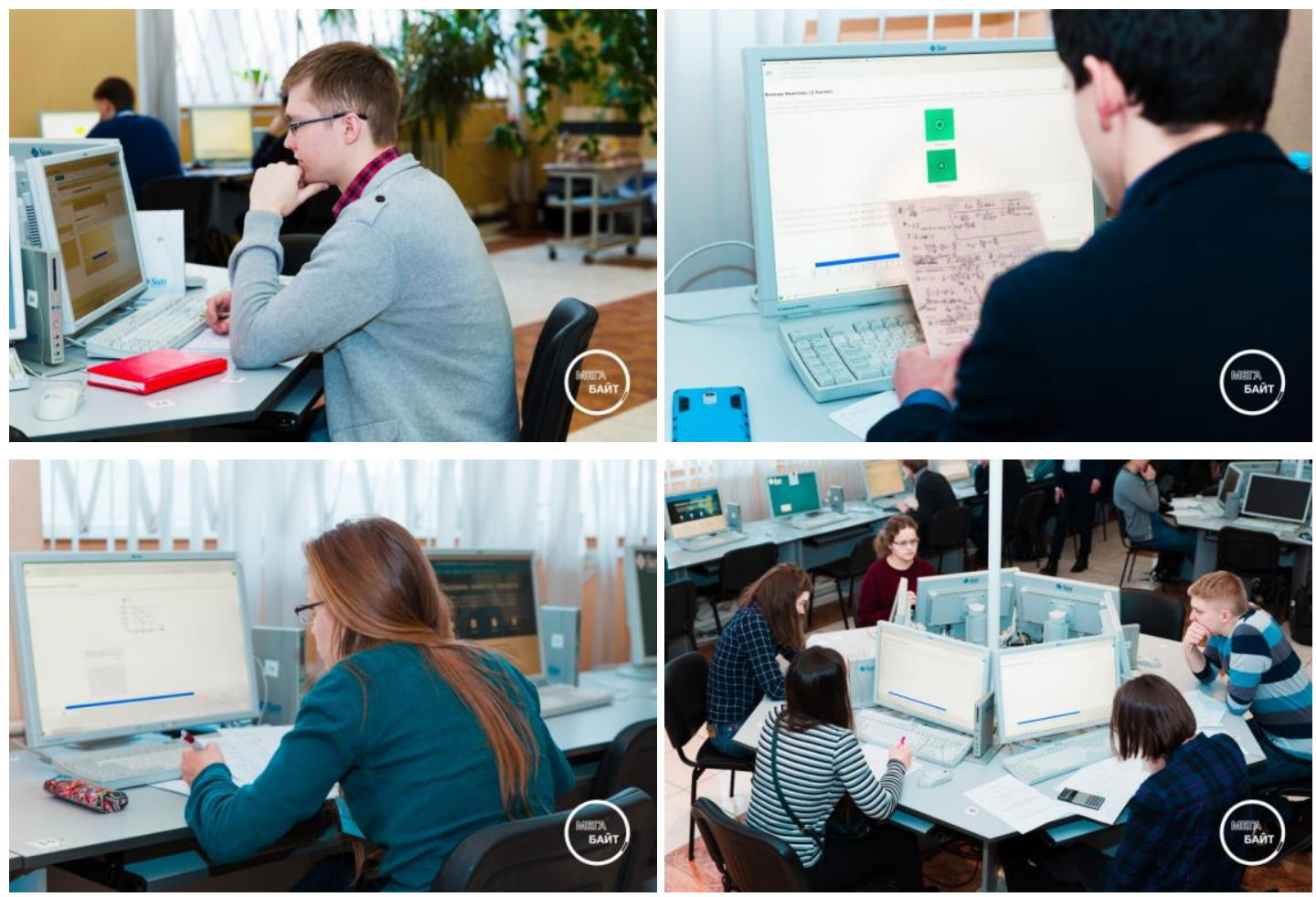

Figure 2. The second round of the competition: the test at the ITMO University (Center of Distant Education)

The test took 2 hours, and the maximum score of points was again 100. From the point of view of some participants it is in fact a blitz, but it allowed choosing the winner who has knowledge both of general principal of photonics and special topics of optics. The winners in two tracks scored about 50 points. 
However, with this form of conducting, there were also some difficulties: first of all, with the shortened preparation times, technical errors are almost inevitable in developing of the test. These mistakes can be a typo in the correct answer, with which the testing system compare participant's answer and the errors of the test authors (it happens rarely). So, for both of this cases, that there was a possibility of applying appeals, and the protocols for passing the test were sent out to the participants within a few days after the round. Additionally, the organizers reviewed the tasks from the point of view of correct task interpretation. Therefore, after the test, approximately 100 participants were reviewed again, and the scores were recounted taking into account the errors found and appeals received. The score distribution for the second round is presented on the figure 3 .

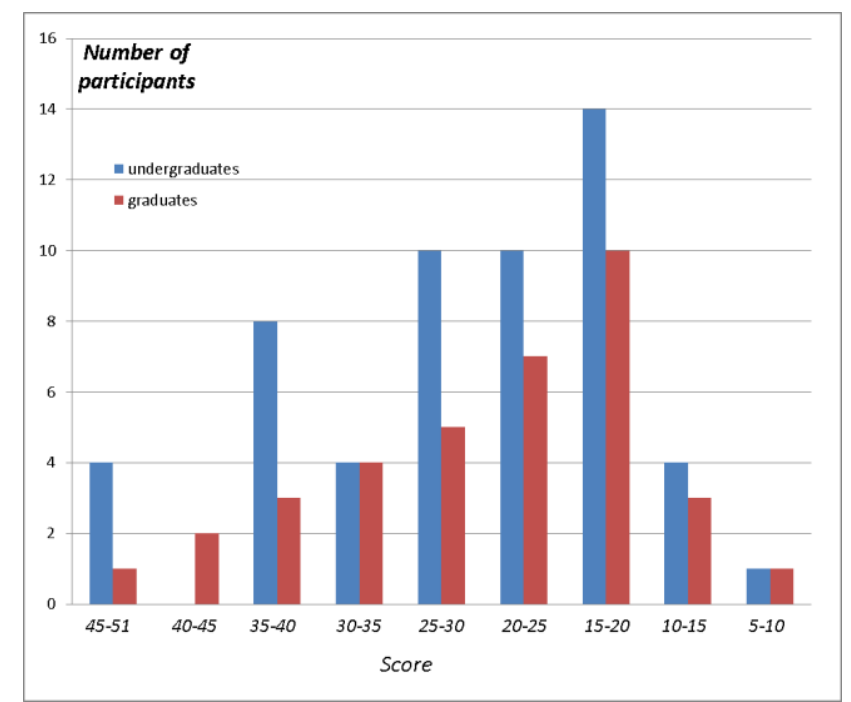

Figure 3. The score distribution of the participants of the second round

For filing appeals, the drafts - the paper with the intermediate calculations of the participants were taken at the time of the completion, so that in case of disagreement and technical mistakes by the participants, the Jury could refer to a draft of the solution made in the presence of the organizers of the Contest.

\section{WINNERS AND AWARDS}

Separately, it is necessary to discuss awards and preferences for the participants. The winners of the first round, who showed the highest score, were given the opportunity to take part in the Winter School (figure 4). Selection for the winter school was based on applications and taking into account the score shown at the qualifying round. For many undergraduate and graduate participants this school was an opportunity to get acquainted with the university and companies and laboratories and it is possible to solve the issue of future admission to the university.
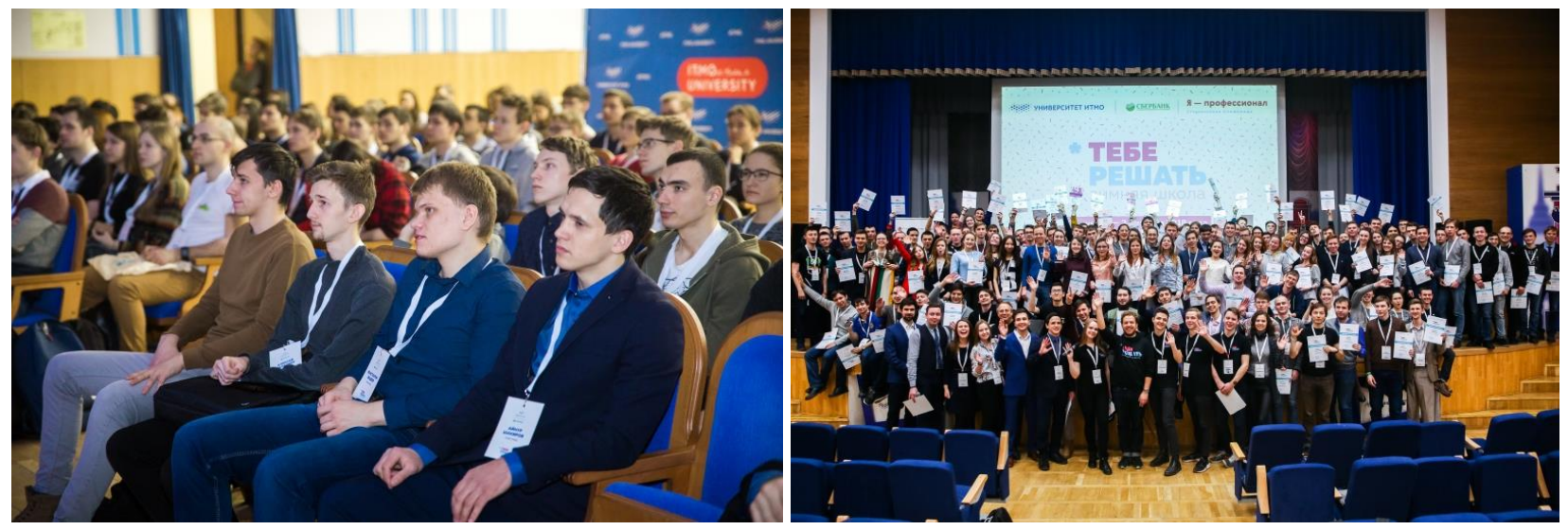

Figure 4. Participants of the Winter School ${ }^{12}$ 
The Winter School is a one-week event, for which participants are offered excursions to companies and scientific and educational centers in St. Petersburg, the scientific laboratories of the ITMO University (figure 5) and the implementation of a team project (the so-called semi-hackathon).

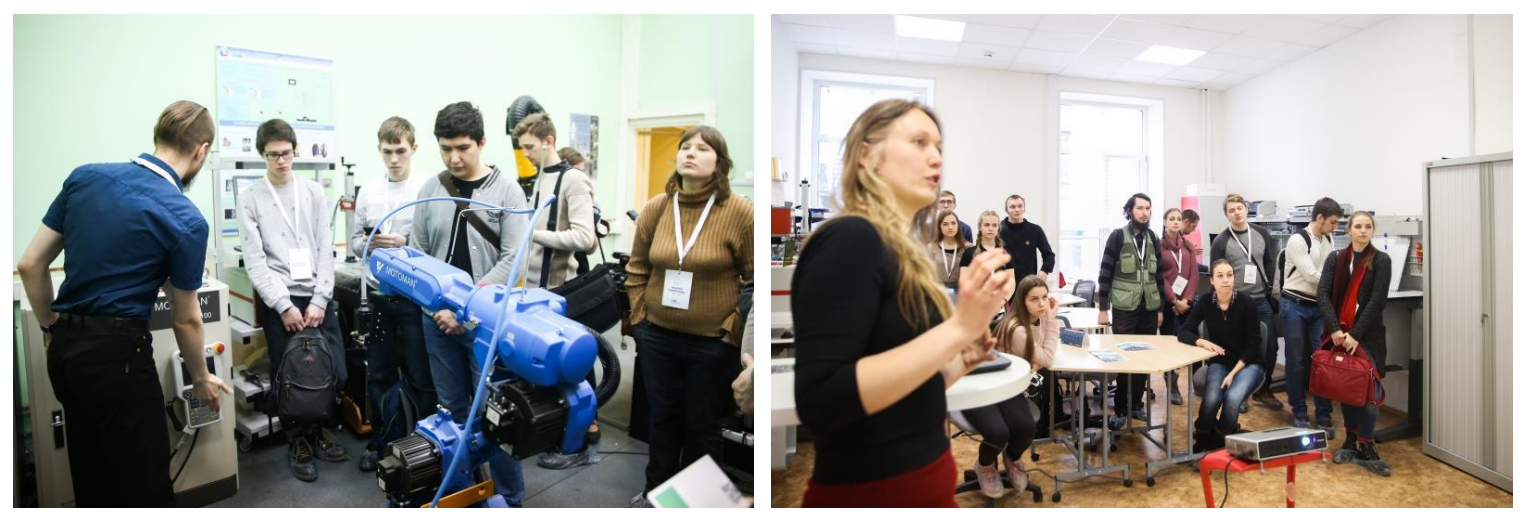

Figure 5. Scientific Laboratories of ITMO University: excursion of the participants to the Laser Processing Lab

The format of the Winter School involved the integration of the participants selected for this event into teams. Since all three directions, attended by the ITMO University, participated in the Winter School, the teams gathered in such a way that every team had representatives from all three directions. Accordingly, the task for semi-hackathon was complex, allowing them to apply knowledge of all three areas.

It is interesting to note that the winner of the event was the team, which managed to present its vision in a short period of time devoted to the project on a given topic, taking into account all areas - Cybersecurity, IT and Photonics. That is, the winners really created a team that worked well during the required time, and each participant was able to contribute to the overall project (on the figure 6 the Winners of the semi-hackathon is shown).

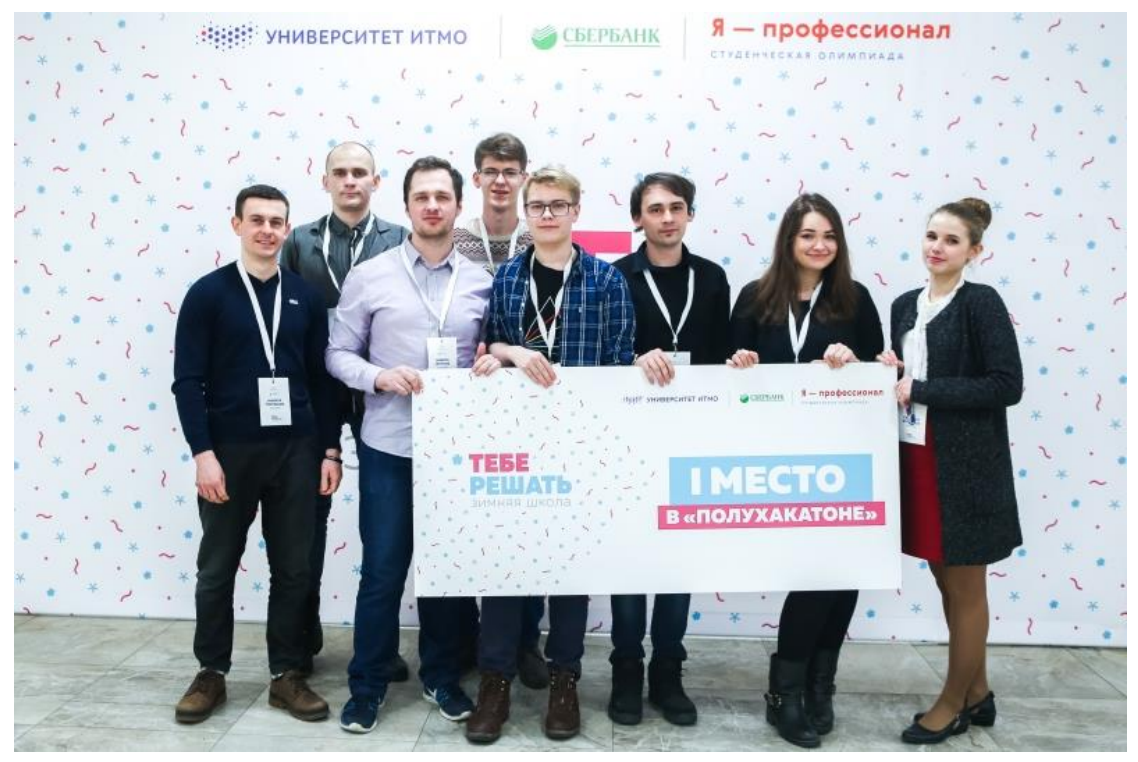

Figure 6. The team - the winners of Semi- Hackathon ${ }^{13}$

\section{DISCUSSION}

In general, based on the results of a large-scale questionnaire, the first approbation of the Contest was positively assessed by the students, as well as by the government of the Russian Federation, the employers' community, organizers and coordinators of the Project. Nevertheless, not all of the goals were achieved. The greatest failure was noted in the organization of internship in the leading companies of the industry for winners. The analysis showed that this problem is complex and related to a number of factors: 
- a low level of business awareness about the Project and a lack of understanding by employers' representatives of their own motivation for participating in the Project,

- failure of the Project's organizers to attract and encourage students to take an internships,

- a disharmonious allocation of places for possible internships territory of the Russian Federation and the location of applicants,

- low levels of soft-skills of modern students that disappoints and turn off the employers,

- low activity and overstated expectations of students on the start of their career.

With the purpose of further promotion of the Contest, the organizers proposed to establish a stable interaction with business leaders in various regions of the Russian Federation, actively involve them both in methodological issues of developing tasks and organizing internships. In addition, it is planned to develop a large on-line course aimed at forming the competencies of soft skills for students

\section{CONCLUSION}

The implementation of the Contest has made it possible to identify the student elite of the Russian Federation - active, motivated and talented, promising both for further education in graduate and postgraduate programs, participation in scientific research, and for implementation in the professional field. The project will provide the winners with a social and professional elevator by including the participants to the young professionals' network through the country.

The Contest also allows identifying the universities which are leaders of education in the field of photonics, and the regions with a developed business and industry infrastructure.

Among the promising areas of the Project development we can find the transfer of the Contest to an English-language format or including the second language, the international status with the provision of the opportunity to participate in the contest of foreign students.

\section{REFERENCES}

[1] ITMO University: http://www.ifmo.ru, en.ifmo.ru

[2] G. E. Romanova, T. V. Tochilina, and A. V. Bakholdin, "Competition in optics for students: organization and realization of the practical and theoretical tours," in ETOP 2015 Proceedings, E. Cormier and L. Sarger, eds., (Optical Society of America, 2015), paper ETM10

[3] All-Russia Contest on Optical Engineering: https://faculty.ifmo.ru/vso

[4] N. Kudryavtzev, "Pick the gold talented", Science and Life, Issue 9 (2010), https://www.nkj.ru/archive/articles/18611/

[5] N. Agakhanov, "Russian students are strong in mathematics," Science and Life, Issue 9, (2010), https://www.nkj.ru/archive/articles/18612/

[6] The system YandexContest: https://contest.yandex.ru/

[7] Siberian State University of Geosystems and Technologies http://sgugit.ru/en/

[8] National Research Nuclear University MEPhI (Moscow Engineering Physics Institute) https://eng.mephi.ru/

[9] Tomsk State University http://en.tsu.ru/

[10] Orel State University http://int.oreluniver.ru/en/

[11] Center of Distant Education of ITMO University https://cde.ifmo.ru

[12] Media Portal ITMO University http://media.ifmo.ru/album/1292/

[13] Media Portal ITMO University http://media.ifmo.ru/album/1297/ 